\title{
Feline Eosinophilic Keratoconjunctivitis: Nonsteroidal vs Corticosteroid Topical Treatment
}

\author{
Gabrielly da Costa Gomes Rodrigues', Ana Maria Tatoni Pereira Coelho', \\ João Pedro Brochado Souza' ${ }^{2}$ Joyce Maira de Araújo' , Márcio Virgílio Figueiredo da Silva', \\ Polyana Mayume Pereira da Silva ${ }^{3} \&$ Gabriel Utida Eguchi ${ }^{1}$
}

\begin{abstract}
Background: Feline eosinophilic keratoconjunctivitis is a proliferative eye lesion of chronic aspect with usually unilateral presentation that may initiate as a superficial vascularization that evolves to a proliferative, granular, irregular lesion of whitish-pink aspect. With its association with an immune-mediated response, nonsteroidal anti-inflammatories do not appear to be efficient, although few studies describe its use. This case report describes a case of a feline eosinophilic keratoconjunctivitis with its clinical evolution since the use of nonsteroidal topical anti-inflammatory drug in an undiagnosed patient and the transition to a topical corticosteroid and cure after 14 days since diagnosis.

Case: An 8-year-old female cat was attended at the Veterinary Hospital of the Dom Bosco Catholic University (UCDB), with main complaint being an eye injury with at least 36 days of evolution and unresponsive to treatment (topical tobramycin $0.3 \%$ every $12 \mathrm{~h} /$ ketorolac trometamol $0.5 \%$ / every $12 \mathrm{~h}$ and ophthalmic lubricant/every $4 \mathrm{~h})$. Since the patient had free access to the street, the owners suspected of trauma-induced lesion. At physical examination, it was observed a proliferative lesion at the peri-limbal superotemporal quadrant of the right cornea with approximately $0.4 \mathrm{~cm}$ diameter, with color varying of pale to pink, with irregular surface and low vascularity, the adjacent conjunctiva was also affected with similar multiple nodular lesions $(0.1 \mathrm{~cm})$. Fluorescein test was negative as well as FIV/FeLV immunochromatography testing. Feline herpesvirus investigation was not possible. The patient was anesthetized and a lesion specimen was acquired with a cotton swab scraping and a fine needle aspiration. Cytology showed predominance of eosinophils and mast cells, with rare corneal epithelial cells, with smear background containing mast cell granules and free eosinophils. Presumptive diagnosis was eosinophilic keratoconjunctivits. After 14 days of topical corticosteroid (prednisolone acetate $1 \%$ every $8 \mathrm{~h}$ ) the patient showed complete remission of the lesions with no relapse in 48 days.

Discussion: Misdiagnosis and consequently mistreatment seems a greater prejudice than the risks associated with sample collection of keratoconjunctival proliferative lesions. Due to the lack of cytobrush or cotton swab, apparently, the reported patient was not submitted to ophthalmic cytology due to reluctance of the staff regarding fine needle aspiration of the cornea lesion. Despite a greater risk of iatrogenic trauma with needle aspiration, with eye anatomy well defined, bevel size and movement amplitude respected, it is unlikely that severe complications could occur. In this case, the undiagnosed patient was submitted to unnecessary 15 days of topical antibiotic and nonsteroidal anti-inflammatory, and no improvement of the clinical signs was observed. Despite non-recommended, few clinical trials as well as case descriptions are available comparing nonsteroidal and corticosteroid treatment of the disease. Once with diagnosis and beginning of topical prednisolone acetate $1 \%$ exclusively, the patient showed continuous improvement until complete remission of clinical signs after 14 days. This report reinforces the recommendation of corticosteroid therapy for feline eosinophilic keratoconjunctivitis and the absence of efficacy of nonsteroidal drugs. It also highlights the importance of diagnosis before any medical treatment is considered.
\end{abstract}

Keywords: corticotherapy, cytology, eosinophilic complex, scraping, swab. 


\section{INTRODUCTION}

Feline eosinophilic keratitis or eosinophilic keratoconjunctivits (FEK) is a proliferative cornea-conjunctiva lesion, possibly associated with an immune-mediated response that may be related with feline herpesvirus infection [4].

Usually, cytology evaluation is sufficient for diagnosis, with eosinophils and mast cells as predominant cells, but sample collection can be challenging considering the different aspects and sizes that ophthalmic lesions may present $[8,12]$.

Treatment involves use of topical corticosteroid or other immunomodulatory drugs, and it is usually curative, while nonsteroidal topical anti-inflammatories (NSAIs) show lack of efficiency [1].

Considering the aspect of potential diagnostic challenge as well as scarce information with the use of NSAIs for FEK treatment, a case report is described focusing on cytology sampling and the comparison between treatment with NSAI and corticosteroid therapy.

\section{CASE}

An 8-year-old domestic short-haired female sterile cat, with the main complaint being an eye injury with at least 36 days of evolution, was attended at the Veterinary Hospital of the Dom Bosco Catholic University (UCDB) - MS. The patient was being treated exclusively with topical drugs [tobramycin ${ }^{1} 0.3 \%$ - one drop every $12 \mathrm{~h}$; ketorolac trometamol ${ }^{1} 0.5 \%$ - one drop every $12 \mathrm{~h}$; and ophthalmic lubricant ${ }^{2}$ - every $4 \mathrm{~h}$ ] and no improvement was observed within 15 days.

It seems that as no cytobrush or cotton swab were available, no sample collection was made considering staff reluctance with fine needle aspiration (FNA) and its possible complications. The owners also considered traumatic-associated injury, since the patient had free access to the street.

At physical examination, it was observed a proliferative lesion at the peri-limbal superotemporal quadrant of the right cornea with approximately 0.4 $\mathrm{cm}$ diameter, with color varying from pale (borders) to pink (center), with irregular surface and low vascularity. The adjacent conjunctiva was also affected with similar multiple nodular lesions $(0.1 \mathrm{~cm})$ [Figure $1 \mathrm{~A}]$.

Fluorescein $^{3}$ test was negative as well as FIV/ FeLV immunochromatography ${ }^{4}$ testing. Feline herpesvirus investigation was not possible.
The patient was anesthetized with intravenous propofol $^{5}$ [induction with $6 \mathrm{mg} / \mathrm{kg} /$ bolus and maintenance with $0.2 \mathrm{mg} / \mathrm{kg} / \mathrm{min}]$. For analgesia, a single dose of methadone ${ }^{5}$ was administered $(0.2 \mathrm{mg} / \mathrm{kg} / \mathrm{IM})$. One drop of anesthetic topical solution ${ }^{6}$ (tetracaine chlorhydrate $1 \%$, phenylephrine chlorhydrate $1 \%$ ) was instilled three min previously to sample collection. Lesion specimen was acquired with a previously dampened (drop of $0.9 \%$ sterile solution) cotton swab scraping $^{7}$ (Figure 1B) and a FNA $\left(25 \mathrm{Gx} 1 / 2^{\prime \prime}\right)^{8}$ [Figure $1 \mathrm{C}]$. The FNA was performed without attachment to a syringe, only with gentle vertical movements in the main lesion. Both procedures were easily performed, with no immediate or post complications observed.

Cytology showed predominance of eosinophils and mast cells, rare corneal epithelial cells, with smear background containing mast cell granules and free eosinophils. Presumptive diagnosis was of eosinophilic keratoconjunctivits [7].

After 14 days of topical corticosteroid [prednisolone acetate $1 \%$ - one drop every $8 \mathrm{~h}$ ] exclusively, the patient showed complete remission of the lesions (Figure1D) with no relapse in 48 days.

\section{DISCUSSION}

The term "eosinophilic keratitis" seems better replaced by "eosinophilic keratoconjunctivitis" since, usually, the conjunctiva is also affected in this disease [4]. That was observed in the patient of this report, which along with a main cornea lesion, also presented smaller nodular lesions of the same color and aspect at the adjacent scleral conjunctiva.

Even when the lesion is of classic description, no aspect of FEK is pathognomonic $[1,4,8,10]$. That considered, routine and easily available complementary tests such as fluorescein dye and cytology should be performed whenever possible.

Cytobrush, commonly used for endocervical sampling in women, found itself as a usable tool in different situations of cytology sampling. Its use on superficial ophthalmic lesions seems already consolidated, with good quality of material acquirement concomitant to minimal injury to the eye $[6,7,12]$. The bristles found on cytobrush probably have more potential to efficiently scrape the lesion than a cotton swab, for example.

Oppositely, fine needle aspiration of cornea and conjunctiva lesions are more prone to complications, since its natural puncture characteristic. The 


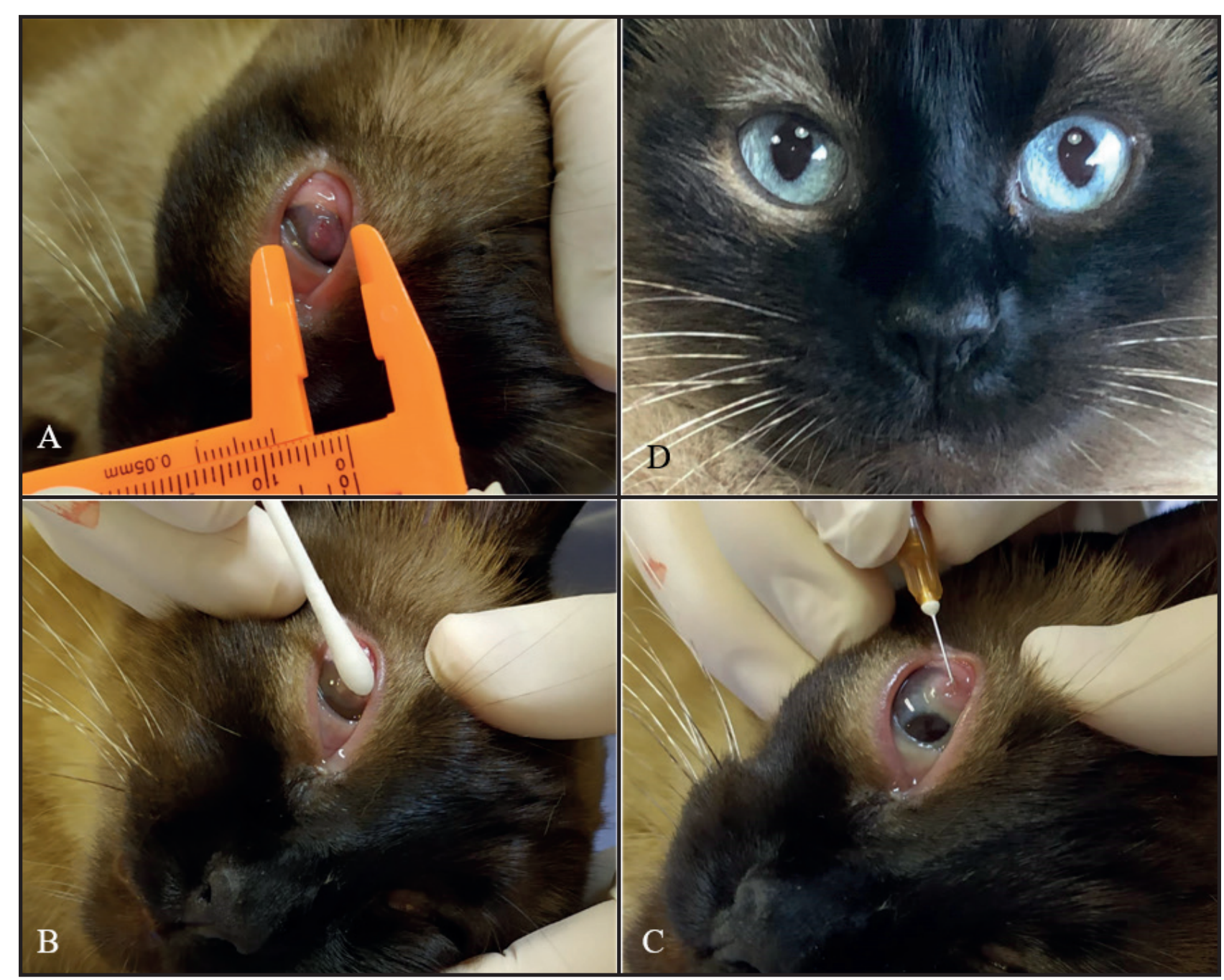

Figure 1. A- An 8-year-old female cat with an eosinophilic keratoconjunctivitis lesion. B- Sampling with a dampened cotton swab scraping. C- Sampling with a $25 \mathrm{Gx} 1 / 2$ " needle. D- Complete remission of the lesion after 14-day treatment with topical prednisolone acetate $1 \%$.

risk of an iatrogenic corneal perforation is higher if compared to a smooth-brush-material object such as the cytobrush [6]. It is understanding that if the professional does not feel secure, such procedure should not be performed and referral should be considered.

Nonetheless, to the author's experience, if the professional recognizes all anatomic structures and takes into account depth of lesion, bevel size and amplitude of movement, any serious iatrogenic lesions would hardly occur. Additionally, for such delicate lesions, it seems that attachment to a syringe and negative pressure would hardly be necessary, as well as would increase the risk of iatrogenic perforations.

A $25 \mathrm{Gx} 1 / 2$ " needle without attachment to a syringe and gentle vertical movements were sufficient for a good sample, allowing diagnosis in this case. Even though no quality graduation was performed, the pathologist noted that the use of fine needle aspiration for preparing slide smears was slightly superior in relationship to cell count evaluation in comparison to the use of cotton swab.

Recommended FEK treatment involves the use of topical corticosteroids and/or immunomodulatory drugs $[4,10]$. It seems that the mechanism of action of corticosteroids in this disease may be associated with controlling the immune response more than its anti-inflammatory effect with inhibition of the synthesis of arachidonic acid, since NSAIs shows absolutely no improvement of the associated lesions in FEK, and drugs such as cyclosporine leads to complete remission and cure $[1,10]$. Topical megestrol acetate $0.5 \%$, a progestin, also appears to be effective in this disease, but despite its glucocorticoid-associated effect, it is not completely elucidated if immunomodulation could also occur $[3,11]$. 
However, the complete mechanism of action remains purely speculation, since no clinical trials were found that considered corticosteroid dose-effect, for example. Topical ophthalmic treatment does not follow the classical dosage based in weight, and that is clearly observed in veterinary patients since cats and horses, both with eosinophilic associated keratitis, virtually receive the same dose of local medication with similar clinical outcomes [4,5]. That postulated, it appears that it is unknown if increase of NSAI topical concentration could have more efficient cyclooxygenase inhibition that would lead to any kind of response in FEK.

Scarce information regarding topical NSAI was found, and despite a case report describing its failure in treating FEK, the name of the principle and concentration were not cited [1]. As for the case described in this report, the use of ketorolac trometamol $0.5 \%$ did not result in any response, and the lesion seemed to be stationary.

If species extrapolation is considered, vernal keratoconjunctivits in humans could be similar to FEK, since eosinophils are the most predominant lesion cell. In that disease, ketorolac trometamol $0.5 \%$ as well as diclofenac sodium $0.1 \%$ have shown to be effective in controlling clinical symptoms (i.e. itching, photophobia) $[2,9]$. Still, even then, topical corticosteroid is the treatment of choice.

In this case, since diagnosis, complete interruption of the previous treatment and institution of monotherapy with topical corticosteroid (prednisolone acetate $1 \%$ ) resulted in progressive improvement of the lesion, with complete remission within 14 days. Since topical tobramycin $0.3 \%$ was also used in the first prescription, it should also be considered the absence of primary bacteria etiology in FEK, since cure was achieved even with discontinuation of the antibiotic. Also, with no indication of bacteria involvement such as cases with purulent discharge, rational use of antimicrobials is advised.

It is expected that this report aid other professionals with impossibility of ophthalmic referral, with guidance such as cytology of proliferative keratoconjunctiva disorders, reinforcing the importance of diagnosis for an effective and focused treatment. It also evidences the inefficiency of topical ketorolac trometamol $0.5 \%$ (NSAI) and tobramycin $0.3 \%$ (antibiotic) in a FEK case.

\section{MANUFACTURERS}

${ }^{1}$ Legrand Pharma Indústria Farmacêutica Ltda. São Paulo, SP, Brazil.

${ }^{2}$ Alcon Laboratórios do Brasil Ltda. São Paulo, SP, Brazil. ${ }^{3}$ Rohto Brasil Holding e Participações Ltda. São Paulo, SP, Brazil. ${ }^{4}$ Alere S/A. São Paulo, SP, Brazil.

${ }^{5}$ Cristália Produtos Químicos Farmacêuticos Ltda. Itapira, SP, Brazil.

${ }^{6}$ Allergan Produtos Farmacêuticos Ltda. Guarulhos, SP, Brazil. ${ }^{7}$ Dalian Goodwood Medical Care Ltd. Dalian, LN, China.

${ }^{8}$ Anhui Easyway Medical Supplies Co. Tianchang, AH, China. ${ }^{9}$ Geolab Indústria Farmacêutica S/A. Anápolis, GO, Brazil.

Declaration of interest. The authors report no conflicts of interest. The authors alone are responsible for the content and writing of the paper.

\section{REFERENCES}

1 Ahn J., Jeong M., Kim S., Park Y., Kim T., Ahn J., Lee S., Lee C. \& Seo K. 2010. A Case of Feline Proliferative Eosinophilic Keratitis Treated by Topical Cyclosporine and Corticosteroids. Journal of Veterinary Clinics. 27(6): 751754.

2 Cortes M., D’Angelo G., Bonini S., Scipioni M., Lamagna A., Sgrulletta R. \& Bonini S. 2002. Preservative Free Diclofenac Sodium 0.1\% for Vernal Keratoconjunctivitis. Investigative Ophthamology \& Visual Science. 43(13): 2229.

3 Day M.J. 2008. Immunomodulatory therapy. In: Maddison J.E., Page S.W. \& Church D.B. (Eds). Small Animal Clinical Pharmacology. London: Saunders, pp.270-286.

4 Dean E. \& Meunier V. 2013. Feline eosinophilic keratoconjunctivitis: a retrospective study of 45 cases (56 eyes). Journal of Feline Medicine and Surgery. 15(8): 661-666.

5 González-Medina S. 2018. Equine eosinophilic keratitis: An emergent ocular condition? Equine Veterinary Education. 31(11): 609-616.

6 Henriksen M.L. \& Lim C.C. 2020. Collection of Ophtalmic Cytology Specimens. In: Sharkey L.C., Radin M.J. \& Seelig D. (Eds). Veterinary Cytology. Hoboken: John Wiley \& Sons, pp.184-187.

7 Peleteiro M.C., Marcos R., Santos M., Correia J., Pissarra H. \& Carvalho T. 2011. Atlas de Citologia Veterinária. Lisboa: Lidel, 308p. 
G.C.G. Rodrigues, A.M.T.P. Coelho, J.P.B. Souza, et al. 2021. Feline Eosinophilic Keratoconjunctivitis: Nonsteroidal vs Corticosteroid Topical Treatment. Acta Scientiae Veterinariae. 49(Suppl 1): 608.

8 Pereira F.Q., Faganello C.S., Bercht B.S., Lacerda L.A. \& Pigatto J.A.T. 2009. Feline eosinophilic keratitis. Acta Scientiae Veterinariae. 37(4): 393-396.

9 Sharma A., Gupta R., Ram J. \& Gupta A. 1997. Topical ketorolac $0.5 \%$ solution for the treatment of vernal keratoconjunctivitis. Indian Journal of Ophthalmology. 45(3): 177-180.

10 Spiess A.K., Sapienza J.S. \& Mayordomo A. 2009. Treatment of proliferative feline eosinophilic keratitis with topical $1.5 \%$ cyclosporine: 35 cases. Veterinary Ophthalmology. 12(2): 132-137.

11 Stiles J. \& Coster M. 2016. Use of an ophthalmic formulation of megestrol acetate for the treatment of eosinophilic keratitis in cats. Veterinary Ophthalmology. 19(Suppl 1): 86-90.

12 Venancio S.A.S., Vieira A.B., Alencar N.X. \& Soares A.M.B. 2012. Avaliação da técnica de esfoliação com escova citológica para coleta de células conjuntivais em gatos sadios: comparação entre a face palpebral da membrana nictitante e a conjuntiva palpebral. Pesquisa Veterinária Brasileira. 32(11): 1199-1204. 